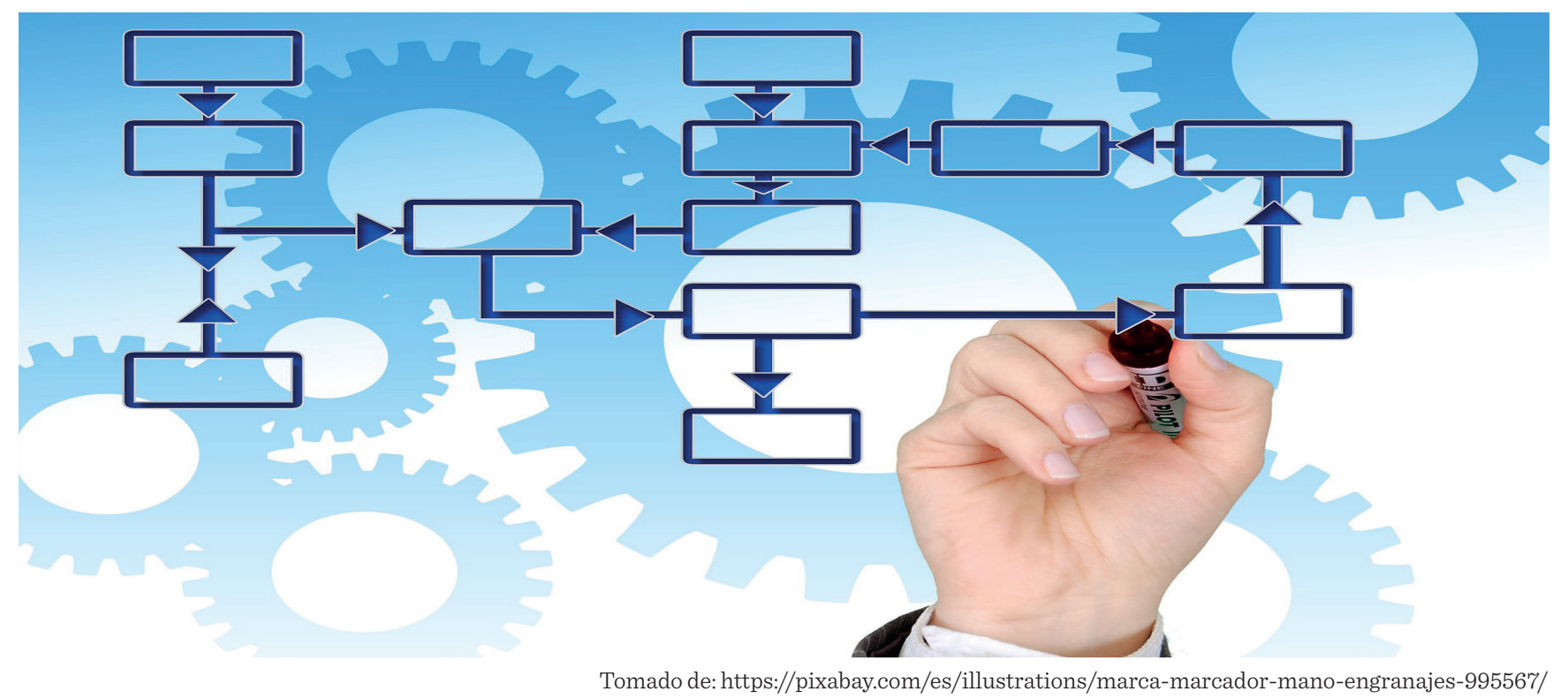

\title{
Desarrollo de habilidades con el uso de instrumentos tecnológicos y la variación
} Development of skills with the use of technological instruments and variation

Jemima de Eden Gutiérrez-Salce ${ }^{1}$, Evelia Reséndiz-Balderas ${ }^{2}$

\section{RESUMEN}

Este trabajo se llevó a cabo en Ciudad Victoria, Tamaulipas, México. El objetivo consistió en desarrollar habilidades en los estudiantes de $1^{\circ}$ de secundaria, a través de instrumentos tecnológicos, para interpretar la variación de situaciones de movimiento, graficarlas y aplicarlo a contextos de la vida cotidiana. Para ello se realizó un cuadernillo de actividades donde estudiantes debían interpretar y graficar situaciones de movimiento, apoyándose con el uso de imágenes con animación de movimiento y el uso de un sensor de movimiento que graficaba en pantalla. Los resultados de este trabajo fueron favorables logrando en cierta medida el objetivo planteado.

Palabras clave: Habilidades, instrumentos tecnológicos, variación, movimiento.

\section{ABSTRACT}

This work was carried out in Ciudad Victoria, Tamaulipas, Mexico. The objective was to develop skills in 1st grade of lower secondary school students, through technological instruments, to interpret the variation of movement situations, to graph them and apply it to contexts of daily life. To do this, an activities booklet was created where students had to interpret and graph motion situations, supporting with the use of images with motion animation and the use of a motion sensor that graphed on the screen. The results of this work were favorable, achieving to some extent the stated objective.

Keywords: Skills, technological instruments, variation, movement.

\footnotetext{
Fecha de recepción: 14/10/2020 Fecha de aceptación: 6/11/2020

${ }_{1}^{1}$ Autor para correspondencia: jemimapaloma94@hotmail.com/Dirección: Universidad Autónoma de Tamaulipas (UAT)/ Estudiante de la Maestría en Gestión e Intervención Educativa de la Unidad Académica Multidisciplinaria de Ciencias Educación y Humanidades (UAMCEH), de la Universidad Autónoma de Tamaulipas (UAT).

${ }^{2}$ Profesora de tiempo completo de la Unidad Académica Multidisciplinaria de Ciencias, Educación y Humanidades de la Universidad Autónoma de Tamaulipas, Maestra en Ciencias con especialidad en Matemática Educativa y Doctora en Ciencias con especialidad en Matemática Educativa, por el Centro de Investigación y de Estudios Avanzados del IPN
} 


\section{INTRODUCCIÓN}

A través de los años se ha evidenciado el bajo desempeño de los estudiantes en la matemática escolar, lo cual ha repercutido en los bajos resultados en pruebas de evaluación. Por otra parte, como se sabe, este problema es muy amplio para pretender que los alumnos de un día para otro obtengan buenos resultados en la materia de matemáticas, es por ello importante atacar una parte del problema con el fin de mejorar el aprendizaje y desempeño de los alumnos.

En análisis a pruebas que se aplican a los estudiantes tamaulipecos, como en otros estados, se ha encontrado bajo desempeño en educación básica en matemáticas, prueba de ello es (PLANEA 2018-2019) de una escuela secundaria ubicada en Ciudad Victoria, Tamaulipas. Los resultados muestran la necesidad de intervenir en ese nivel educativo, ya que la mayoría de los alumnos se encuentran en el nivel I, que es el nivel más bajo (los estudiantes muestran una menor cantidad de aprendizajes). Los alumnos que se encuentran en ese nivel, no han logrado adquirir la habilidad para: traducir al lenguaje algebraico a una situación que se modela con una ecuación lineal, para resolver problemas que implican comparar el volumen de cilindros de manera visual, resolver problemas que implican estrategias de conteo básicas (representación gráfica). Por otra parte, se ha encontrado en educación secundaria y bachillerato que los jóvenes presentan problema al interpretar las gráficas y al usarlas (Saucedo, 2014). Así como, la interpretación gráfica del movimiento con las variables distancias/tiempo, son leídas como trayectorias de movimiento y no así, como una relación de dos variables (Briceño y Cordero, 2012).

En el Programa de estudios de educación secundaria en Matemáticas, en $1^{\circ}$ grado en el tema de funciones; sus aprendizajes esperados son (refiriéndose al alumno): analiza y compara situaciones de variación lineal a partir de sus representaciones tabular, gráfica y algebraica.

Interpreta y resuelve problemas que se mode- lan con estos tipos de variación; lo cual con este trabajo, se espera favorecer (SEP, 2017).

El objetivo de este trabajo es desarrollar habilidades en los estudiantes de $1^{\circ}$ de secundaria, a través de instrumentos tecnológicos, para interpretar la variación de situaciones de movimiento, graficarlas y aplicarlo a situaciones de la vida cotidiana. Para ello se realizó un cuadernillo de trabajo con ciertas actividades donde se presentaban ciertas situaciones de movimiento, dichas actividades tomaron como referente del Capítulo 1: Conozca al señor movimiento, de los autores Briseño y Cordero, 2015 en el libro; La Ciencia desde el niño(a) (Cordero, 2015), se encontró el nivel de complejidad y se adaptó y rediseñó para ser utilizado con estudiantes de secundaria. Como apoyo visual, a esas actividades del cuadernillo se realizó las mismas actividades en Power Point la adaptación consiste en tomar imágenes de licencia libre de PIXABAY y se insertaron en diapositivas de Power Point, dándoles movimiento con el botón de animación para hacer más real la situación presentada a los estudiantes de secundaria.

El supuesto de esta intervención es que mientras haya más integración de instrumentos tecnológicos en clase de matemáticas, mayor será el desarrollo de habilidades en los estudiantes de $1^{\circ}$ de secundaria, para que puedan tener una interpretación gráfica de situaciones de movimiento.

La teoría que sustenta este trabajo de intervención, es la teoría socioepistemológica o teoría de situaciones de aprendizaje, ya que para este trabajo se pretende que los alumnos desarrollen habilidades a través de instrumentos tecnológicos para interpretar la variación se situaciones de movimiento, graficarlas y aplicarlo a situaciones de la vida cotidiana, se pretende los estudiantes puedan ver que la matemática se encuentra en todas partes y la usamos constantemente. Como menciona Cantoral (20 16) sobre la socioepistemología:

Postula que para atender la complejidad de 
la naturaleza del saber y su funcionamiento al nivel cognitivo, didáctico, epistemológico y social en la vida de los seres humanos, deberá de problematizar al saber [...] situándolo en el entorno de la vida del aprendiz (individual o colectivo) [...] (p.51).

Por ello, en este trabajo se pretende abordar el tema de variación, en donde a los alumnos se les planteen diversas situaciones de movimiento, de actividades que realizan cotidiana mente, por ejemplo, caminar, ya sea lento o rápido, ir y regresar a un lugar a distinta velocidad, entre otros, y graficar su movimiento. No solo se espera realicen esto en el cuadernillo de trabajo, sino que hagan la misma actividad del cuadernillo con su cuerpo, que realicen diversos desplazamientos frente a un sensor de movimiento, el cual hará una gráfica (en pantalla), del movimiento que realice cada alumno frente a él.

Como se sabe, existen muchos temas de matemáticas que la mayoría de los alumnos no logran comprender, una de las causas evidentes es que no logran ver el uso de la matemática en su vida diaria, por ello, en este proyecto se preten de además de desarrollar habilidades en los estudiantes en el tema de variación, para que grafiquen, interpreten, entre otros, que los alumnos puedan darle sentido a lo que están aprendiendo en la clase de matemáticas, ver el uso de ella en su vida cotidiana.

Por ello en este proyecto se hace referencia al enfoque socioepistemológico ya que este pone su foco en la práctica social del conocimiento, todo ello con el fin de crear diseños de ello para la intervención didáctica (Cantoral y Farfán, 2008). Por otra parte y en cuanto al uso de herramientas tecnológicas en el aula, en este proyecto se toma a la tecnología como un factor clave para la enseñanza de las matemáticas ya que juega un papel importante no solo en la forma de enseñar y aprender las matemáticas sino en lo que se enseña (Correa, Reséndiz, Salazar y Sánchez, 2016).
Uno de los enfoques teóricos en investigación para la integración de la tecnología digital en la educación matemática es la aproximación instrumental, la cual señala que todo aprendizaje con noción matemática esta mediado por instrumentos, esto ocurre con el saber matemático, las acciones del profesor, el conocimiento construido por el alumno, la organización de la clase y el uso didáctico del instrumento (Santacruz, 2009).

En otras palabras, el enfoque de aproximación instrumental, se preocupa por los aspectos instrumentales de la actividad de uso de una herramienta tecnológica por parte de un sujeto en un contexto educativo, se encarga de formar artefactos en instrumentos de actividad matemática.

\section{METODOLOGÍA}

Método: Este trabajo realizado con el método cualitativo, llevado a cabo en la Escuela Secundaria Federalizada No.1 "Dr. Norberto Treviño Zapata" turno matutino, ubicada en Ciudad Victoria Tamaulipas. Se hizo entrega a los estudiantes de $1^{\circ} \mathrm{C}$ un cuadernillo de actividades en donde se presentaron ciertas situaciones de variación de movimientos y los estudiantes debían describir, graficar e interpretar dicho movimiento.

Como estrategia fundamental para este proyecto se establece la siguiente: Desarrollo de habilidades para interpretar y graficar situaciones de movimiento en el grupo de $1^{\circ} \mathrm{C}$ de secundaria. Para el logro y realización de esta estrategia, se implementa una serie de actividades que estimulen en los estudiantes el desarrollo de habilidades para la interpretación gráfica de situaciones de movimiento en hoja de papel y a través del uso de la Tecnología Educativa, en un salón de primer año de la Escuela Secundaria Federalizada No1 "Dr. Norberto Treviño Zapata” turno matutino, Ciudad Victoria Tamaulipas, en clase de matemáticas.

Se hizo un informe de selección, cambios de actividades, y rediseño de actividades del Capítulo 1: Conozca al señor movimiento, de los 
autores Briseño y Cordero, 2015 en el libro; La Ciencia desde el niño(a) (Cordero, 2015). En donde se presentan diversas situaciones de movimiento. Con base en ello se crea un cuadernillo de trabajo con 10 actividades, una vez seleccionadas y rediseñadas las actividades sobre el tema de variación, se imprimieron en hoja de papel, 18 páginas a blanco y negro, y 41 copias para cada repartir a cada uno de los alumnos.

Para ello también se incluye un trival (diapositivas de Microsoft Power Point) con 10 actividades animadas con imágenes clasificadas, que sirvan como apoyo a las situaciones de movimiento que se presentan en cada uno de los cuadernillos de trabajo. Para este trabajo, se cuenta con recursos materiales como, aula equipada con proyector (cañón), mesa bancos, pantalla, espacio adecuado para interactuar, cortinas en el salón, cosas con las cuales cuenta la Escuela Secundaria Federalizada No.1 "Dr. Norberto Treviño Zapata". Por otra parte, la interventora cuenta con los siguientes recursos; un tripié para colocar el sensor de movimiento, un sensor de movimiento, una calculadora CASIO con los respectivos cables y elementos para poder realizar los gráficos y pasar dichos gráficos de la calculadora a la laptop en aplicación Screen Receiver y de la laptop a proyección en pantalla mediante el proyector.

También se cuenta con una laptop con la aplicación instalada de Screen Receiver (para poder proyectar los gráficos que realice el sensor), la aplicación se Microsoft Power Point, y se cuenta con el cable HDML para poder proyectarlo en pantalla mediante el proyector, así mismo se cuenta con un celular Smartphone para tomar fotos y videos de la realización de cada una de las actividades por los estudiantes, tanto en el cuadernillo como en el uso del sensor de movimiento.

Procedimiento de la intervención: Se entregó un cuadernillo de trabajo a los alumnos con actividades, rediseñadas del Capítulo 1: Conozca al señor movimiento (Cordero 2015), se presen- taron situaciones de movimiento, posteriormente se mostraba en pantalla (mediante cañón y laptop) el trayecto de la actividad (con imágenes de un personaje llamado "Victoria", con animación de movimiento en diapositivas de Power Point), los alumnos debían responder en el cuadernillo la descripción del movimiento visto en pantalla (del trayecto de Victoria).

En otras actividades del cuadernillo los alumnos tenían que dibujar una gráfica en un plano cartesiano del movimiento que se les presentaba en pantalla, posteriormente se utilizaba un sensor de movimiento en el cual los alumnos se desplazaban frente a él, de un lugar a otro caminando a distinta velocidad o deteniéndose en una parte del trayecto, según la actividad lo marcaba y en pantalla a través de la aplicación Screen Receiver se dibujaba la gráfica de su movimiento, así los alumnos podían corroborar si la gráfica que habían hecho antes de utilizar el sensor de movimiento, les había quedado parecida a esa; así mismo los alumnos respondían ciertas preguntas de la actividad como: ¿En dónde hizo más tiempo Victoria, al ir o al regresar? ¿Cómo se ve en la gráfica el hecho de que Victoria estuvo detenida? Entre otros.

\section{RESULTADOS}

Este trabajo se aplicó a estudiantes de la Escuela Secundaria Federalizada No.1 "Dr. Norberto Treviño Zapata” turno matutino, a los alumnos de $1^{\circ} \mathrm{C}$, en Ciudad Victoria Tamaulipas. Al momento de presentarles a los alumnos de $1^{\circ} \mathrm{C}$ el cuadernillo de trabajo o situación de aprendizaje, se pudo observar que los alumnos no sabían cómo graficar en un primer momento, pero después al presentarles la misma situación del cuadernillo mediante diapositivas, de una situación de movimiento de la vida cotidiana como es, una niña caminando a cierta velocidad hacia un árbol (esta imagen o diapositiva teniendo animación) los estudiantes podían comprender más de que se trataba y con mayor facilidad graficaban la situación que se les mostraba, posteriormente al utilizar el sensor de movimiento y ellos realizar con su propio cuerpo el movimiento que se presentaba en la 
actividad del cuadernillo y en la diapositiva, podían verificar si su grafica se veía igual de la que el sensor mostraba en pantalla.

Al principio hubo muchos que corregían su gráfica después de utilizar el sensor y comprobar cómo quedaría, pero después de utilizar varias veces el sensor, podían realizar con mayor facilidad los gráficos antes de comprobarlos con su propio movimiento. Esto muestra que evidentemente los alumnos fueron desarrollando esa habilidad para poder interpretar anticipadamente cómo quedaría la gráfica en cada una de las actividades del cuadernillo, algunos llegaron al grado de poder identificar cuando algún gráfico de sus compañeros no era el apropiado a la situación de movimiento presentada.

Por otra parte, los alumnos tenían cierto conocimiento sobre el tema de variación de movimiento ya que podían describir con palabras, pero no tenían la idea de cómo graficar un movimiento, pero a través del uso de los instrumentos tecnológicos pudo ser posible, también se encontró, los alumnos no tienen la noción de las variables distancia/tiempo pero pudieron graficar e interpretar la forma en la que se dibujan ciertos movimientos.

En el cuadernillo de trabajo presentado a los alumnos con el propósito de tener evidencia escrita de su interpretación y análisis de las situaciones de movimiento presentadas, se encontró lo siguiente en sus respuestas.

Se presentó una actividad de inicio, como la siguiente:

Actividad de inicio: "La carrera"

En una escuela secundaria un maestro quiere

Figura 1. Respuesta de alumno a.

Figure 1. Student response a. mostrar a sus alumnos la importancia de cuidarse y hacer ejercicio, por lo cual realiza una carrera con algunos de sus estudiantes de $1^{\circ}$ año, elije a 4 estudiantes: Juan, Ana, Jimena y Daniel. El maestro lleva a todos sus alumnos al patio de la escuela, coloca una señal de inicio de la carrera y final de la carrera, en total son 100 metros que recorrerán. El maestro explica las reglas de la carrera, diciendo que; lo importante no es ganar sino hacer todo el recorrido cada quien a su paso, y la carrera empieza.

*Mira la siguiente diapositiva que muestra (con animación de movimiento), cómo fue el recorrido de cada uno de los estudiantes. Responde las siguientes preguntas sobre cómo fue el movimiento (inicio, durante y final de la carrera, si iban lento, rápido, entre otros) de Juan, Ana, Jimena y Daniel en el trayecto:

Describe, ¿cómo fue el movimiento durante el recorrido de Juan?

Describe, ¿cómo fue el movimiento durante el recorrido de Ana?

Describe, ¿cómo fue el movimiento durante el recorrido de Jimena?

Describe, ¿cómo fue el movimiento durante el recorrido de Daniel?

Aquí los estudiantes debían dar respuesta a las cuatro preguntas y contestaron lo siguiente:

A continuación se presentará la respuesta que escribieron la mayoría de los estudiantes, comparando aquí la de dos alumnos que representan el ejemplo de la mayoría de las respuestas encontradas.

Alumno a

\section{Describe, ¿cómo fue el movimiento durante el recorrido de Juan? lento y rapido.}


Alumno b

Figura 2. Respuesta de alumno b.

Figure 2. Student response b.

\section{Describe, ¿cómo fue el movimiento durante el recorrido de Juan? Al principio foe amedicición y al uttimo fue rapido.}

La mayoría de los estudiantes en la primera pregunta. Describe, ¿cómo fue el movimiento durante el recorrido de Juan? respondieron que inició su recorrido lento y después fue rápido (ejemplo, alumno a), otros alumnos fueron más específicos en la descripción del recorrido y respondieron que al principio fue a mediación o medio rápido y al último fue rápido (ejemplo alumno b).

Alumno a

Figura 3. Respuesta de alumno a.

Figure 3. Student response a.

Describe, ¿cómo fue el movimiento durante el recorrido de

$$
\begin{aligned}
& \text { Ana? primero fue demasiado lento y despues } \\
& \text { muy rapido. }
\end{aligned}
$$

Alumno b

Figura 4. Respuesta de alumno b.

Figure 4. Student response b.

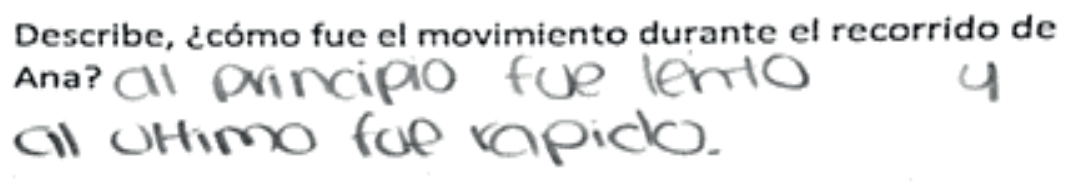

En la segunda pregunta. Describe, ¿cómo fue y después muy rápido, otros escribieron que el movimiento durante el recorrido de Ana? al- al principio fue lento y al último fue rápido. gunos de los estudiantes respondieron como el estudiante a, primero fue demasiado lento Alumno a

Figura 5. Respuesta de alumno a.

Figure 5. Student response a.

Describe, ¿cómo fue el movimiento durante el recorrido de

Jimena? Primero rapido y al final

$$
\text { despacio. }
$$


Figura 6. Respuesta de alumno b.

Figure 6. Student response b.

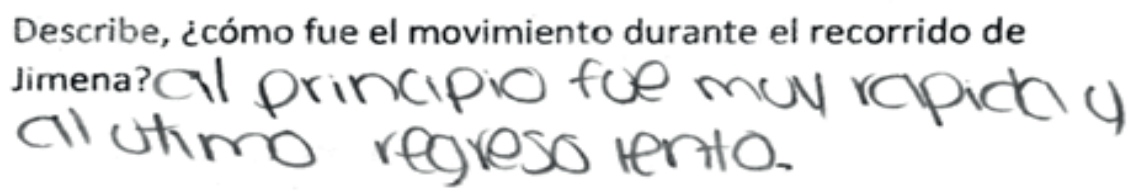

En la tercer pregunta. Describe, ¿cómo fue el movimiento durante el recorrido de Jimena? Algunos estudiantes respondieron como el alumno a, sobre el recorrido de Jimena, que primero fue rápido y al final despacio, otros respondieron como el alumno b, que al principio de su recorrido fue muy rápido y al último regresó lento. Alumno a

Figura \%. Respuesta de alumno a.

Figure 7. Student response a.

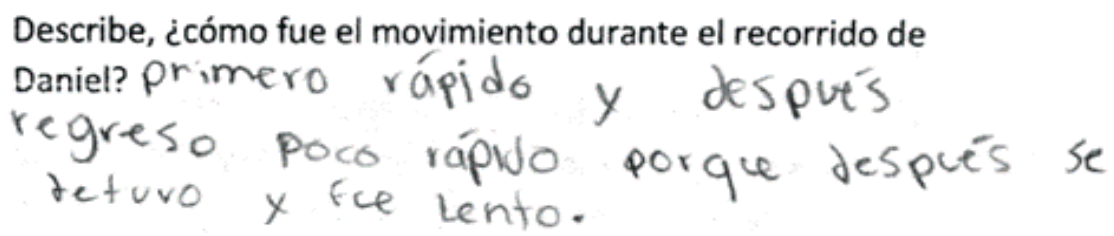

Alumno b

Figura 8 Respuesta de alumno a.

Figure 8. Student response a.

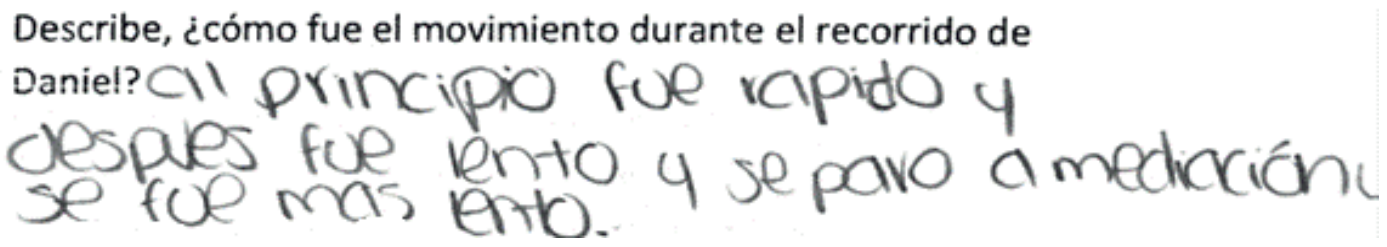

En la cuarta pregunta. Describe, ¿cómo fue el movimiento durante el recorrido de Daniel? respondieron que primero fue rápido y después regresó poco rápido porque después se detuvo y fue lento (ejemplo alumno a), otros respondieron que al principio fue rápido y después lento y se paró a mediación y se fue más lento (ejemplo alumno b).

En esta actividad de inicio se puede observar que los alumnos tienen en claro la noción de velocidad, es por ello que no tuvieron ninguna dificultad al momento de escribir sus respuestas, ya que en ellas señalan que tan rápido o lento fueron los recorridos de Juan, Ana, Jimena, y Daniel. La similitud o diferencia que se encontró en esta actividad es que algunos alumnos fueron más específicos en describir la velocidad de cada recorrido, pero a grandes rasgos las respuestas fueron muy similares en los cuadernillos de trabajo de los 39 alumnos. A continuación se presenta la actividad 1.

\section{Victoria y el Observador}

En la siguiente imagen se muestra un personaje que llamaremos el Observador y que representará el origen del sistema cartesiano. El observador se toma como punto inicial, a partir del cual se calcula la distancia de Victoria (una joven como tú) al desplazarse hacia un árbol en un tiempo transcurrido.

Para estas actividades el Observador es el padre de Victoria: quien representará el inicio del recorrido que ella realiza. El recorri- 
do se lleva a cabo en un campo que se encuentra cerca de la casa de los abuelos de Victoria.

\section{Actividad 1}

En la actividad 1, Victoria hace un recorrido partiendo desde el observador, va caminando a una velocidad considerable hasta llegar al árbol, se da la vuelta y regresa hacia el observador con la misma velocidad con la que llegó. *Mira la siguiente diapositiva que muestra (con animación de movimiento), cómo fue el recorrido de Victoria. ¿Cómo sería la gráfica del movimiento que realizó Victoria?
Dibújala en el siguiente plano cartesiano Antes de empezar con el análisis de la actividad 1 , cabe recalcar que primero se procedió a que cada alumno leyera las instrucciones de la actividad, posteriormente se le mostraba en diapositivas con animación de movimiento, el recorrido que realiza Victoria, quien es el personaje principal de estas actividades, y después los estudiantes procedían a graficar en el plano cartesiano según entendieran, y por último se utilizaba el sensor de movimiento para que un estudiante pasara al frente e imitara el movimiento del recorrido de Victoria y en pantalla se mostraba como debería quedar la gráfica

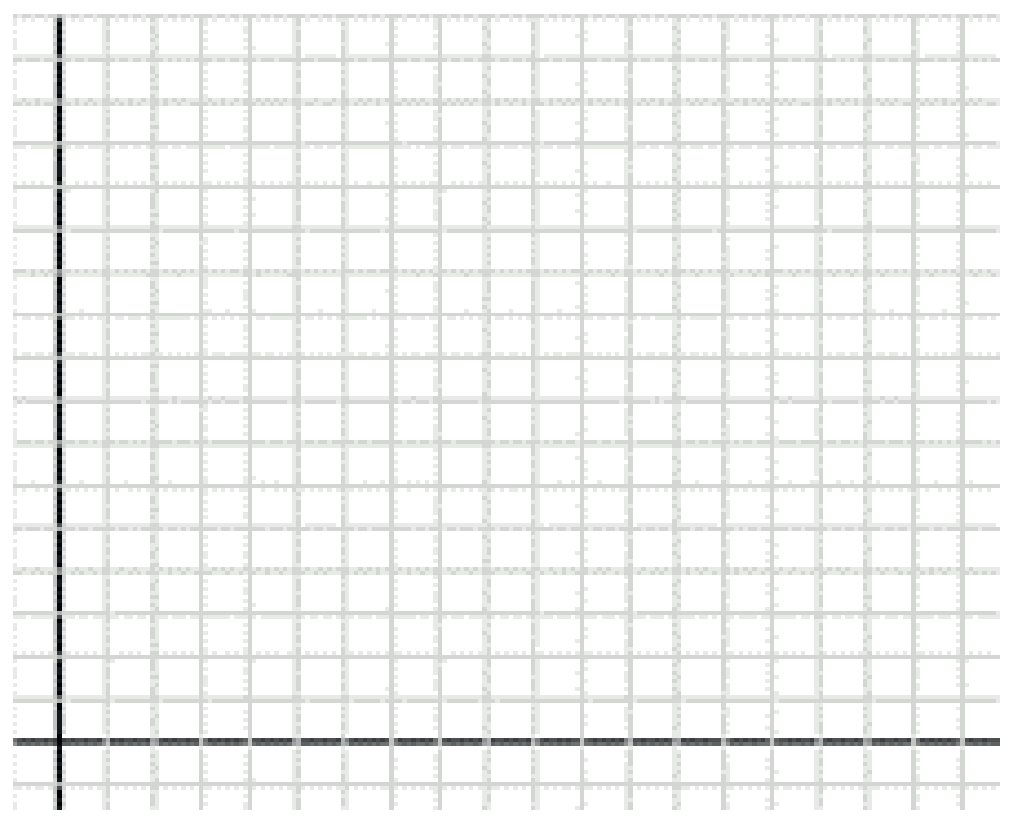


y así corroborar con la gráfica que habían realizado antes los alumnos para validar conjeturas. A continuación se presentan las gráficas que hicieron los alumnos en respuesta a la pregunta de la actividad 1, sobre ¿Cómo sería la gráfica del movimiento que realizó Victoria?

\section{Alumno a}

Figura 9 Respuesta de alumno a.

Figure 9. Student response a.

\section{¿Cómo sería la gráfica del movimiento que realizó Victoria?} Dibújala en el siguiente plano cartesiano.

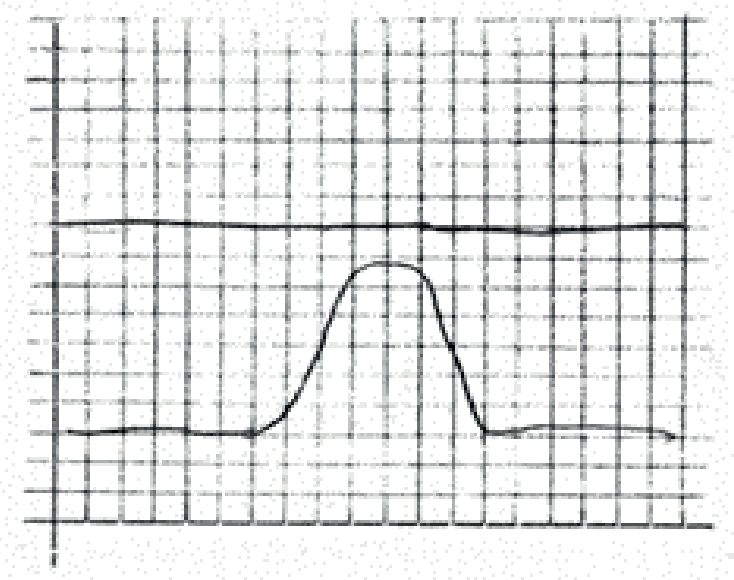

Esta gráfica (alumno a) representa a la mayoría de los estudiantes, ya que hicieron una gráfica en forma de línea recta, en un primer momento, pero después al utilizar el sensor de movimiento pudieron observar que la gráfica queda en forma de montaña, y así la graficaron después.

Alumno b Solo algunos cuantos alumnos (como

Figura 10. Respuesta de Alumno b.

Figure 10. Student response b.

¿Cómo sería la gráfica del movimiento que realizó Victoria? Dibújala en el siguiente plano cartesiano.

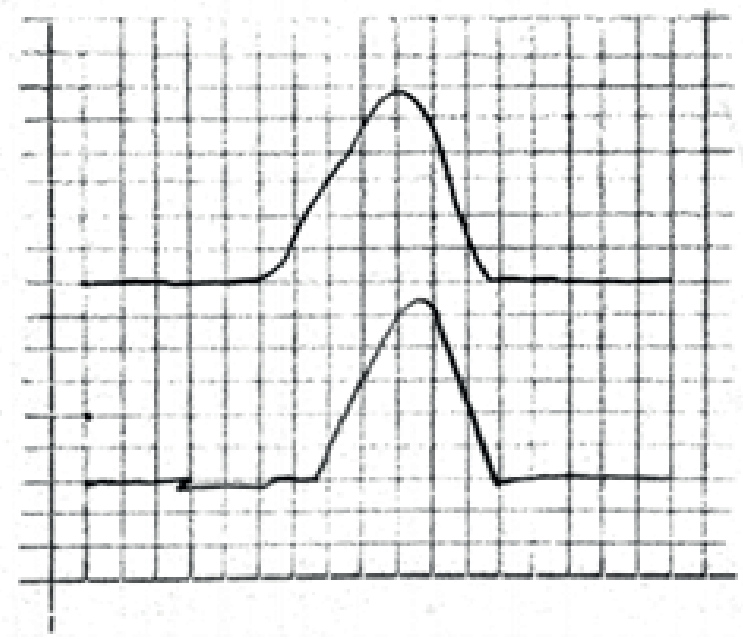


es el caso del alumno b), pudieron graficar en un primer momento el movimiento de Victoria en forma de montaña, en plano aparecen dos gráficas ya que una fue hecha por ellos antes de utilizar el sensor, y otra después de hacerlo, esto para que ellos vieran la diferencia entre su gráfica inicial a la posterior.

Cómo se puede observar solo algunos pocos alumnos como es el caso del alumno b, tienen cierta noción de cómo se forma una gráfica con determinado movimiento o velocidad, pero como se puede observar en el alumno b, desconocen que la gráfica empieza desde el punto cero, es por ello que probablemente empezaron a graficar en donde ellos creyeron conveniente.

En el caso del alumno a, que representa a la mayoría de las respuestas de los estudiantes si tenían un desconocimiento mayor de cómo se podría formar una gráfica con determinado movimiento.

Estos solo son algunos ejemplos de actividades del cuadernillo que respondieron los alumnos de $1^{\circ} \mathrm{C}$, y a través del análisis a las respuestas de los estudiantes en cada una de las actividades del cuadernillo de trabajo, se puede decir que lograron desarrollar en cierta medida la habilidad para interpretar la variación de las situaciones de movimiento, graficarlas y a través del uso del sensor y de su propio cuerpo para realizar los movimientos pudieron aplicar ese conocimiento en una situación real o de la vida cotidiana como es el caminar, a distinta velocidad.

\section{CONCLUSIONES}

Los resultados obtenidos confirman que al hacer uso de instrumentos tecnológicos apropiados sirviendo como apoyo en temas impartidos en clase de matemáticas, no solo existe motivación de los estudiantes por aprender e utilizar los instrumentos, sino que en verdad logran una mejor comprensión del tema. Antes de mencionar las reflexiones y conclusiones de este proyecto, se exponen algunos trabajos que se han encontrado con cierta similitud a este proyecto, en los cuales se realza el uso de instrumentos tecnológicos en el proceso de aprendizaje de las matemáticas.

En un trabajo titulado, Reflexión didáctico-matemática de profesores en formación inicial a través del diseño de tareas matemáticas; cuyo objetivo es mostrar el diseño y el análisis de una actividad didáctica que promueve el desarrollo de conocimientos didáctico-matemáticos en futuros profesores de secundaria de matemáticas sobre el tema variación lineal. En sus resultados se revela la necesidad de plantear este tipo de tareas para favorecer conocimientos didáctico-matemáticos en futuros profesores (Herrera y Dávila, 2020).

En ese trabajo se utilizan algunos recursos didácticos para enseñar a los profesores actividades que pueden exponer a sus alumnos, por otra parte se hace mención al uso de la herramienta tecnológica como es GeoGebra, entre otros. Cabe resaltar que aquí se realza la necesidad de hacer más didáctica (atractiva, diferente, no ordinaria) la clase de matemáticas para este tipo de temas ya que no solo será atractivo para los alumnos sino que existe mayor probabilidad de que estos aprendan lo requerido por el simple hecho de que algo no común en clase llamará su atención.

Por otra parte, en un trabajo titulado Percepciones hacia el uso de la tecnología en la enseñanza de las matemáticas en estudiantes normalistas. El estudio forma parte del diagnóstico de una investigación titulada: Uso de la tecnología para fomentar el álgebra temprana, en el que se busca conocer las percepciones de estudiantes normalistas de la Licenciatura en Educación Primaria. Los resultados que se obtuvieron evidencian una gran oportunidad de desarrollar actividades que ayuden a los estudiantes para incorporar la tecnología, y por otra parte se encuentra la limitante de que en ocasiones no todos los docentes incorporan las tecnologías y muchas veces estas son de un alto costo (Ibarra y Rodríguez, 2020).

En estos dos trabajos se puede rescatar que efectivamente el incorporar el uso de la tecno- 
logía en la clase de matemáticas se obtienen más resultados positvos que negativos, por otra parte se necesita realizar un efuerzo por incorporarlas.

En el caso de esta intervención al hacer uso de instrumentos tecnológicos en una clase de matemáticas con alumnos de $1^{\circ}$ en el tema de variación, mediante una situación de aprendizaje para que desarrollaran habilidades para interpretar la variación de situaciones de movimiento, graficaran y vieran el significado o el uso de la matemática en la vida cotidiana, funcionó. Ya que, se pudo observar como los estudiantes en un inicio no sabían cómo graficar la situación de movimiento que se presentaba, pero al momento de representar el trayecto marcado en el cuadernillo de trabajo, por medio de diapositivas con imágenes representando el movimiento que venía en la actividad, podían entender cómo quedaría la gráfica, por otro lado, al hacer uso del sensor de movimiento podían corroborar si su gráfica había quedado bien.

Esos eran los pasos primero los alumnos en el cuadernillo de trabajo leían la actividad o situación que se presentaba de algún trayecto de una persona, posteriormente veían esa representación por medio de diapositivas en Power Point donde mostraba con animación de movimientos los trayectos, por ejemplo, una imagen de una niña caminando de manera rápida hacia un árbol y regresar al inicio de su recorrido caminando lento, después ellos tenían que graficar ese movimiento y posteriormente con el uso del sensor, participaba uno de los alumnos, se posicionaba frente al sensor e imitaba el trayecto de la niña de la actividad presentada, el alumno(a) de secundaria caminaba a cierta distancia imaginando que camina hacia el árbol lo hace de manera rápida y regresa de manera lenta.

Así al usar varias veces el sensor, y continuar con las actividades del cuadernillo, los estuidiantes podían graficar antes de utilizar el sensor y decir cómo quedaría la gráfica, eso mostró un desarrollo es sus habilidades para interpretar las situaciones de movimiento y poder graficarlas.
Como se sabe, los instrumentos tecnológicos son atractivos a las nuevas generaciones, con el simple hecho de haberlos usado en clase de matemáticas (lo cual, no es muy común), provocó interés en los estudiantes por el tema, comprendieron mejor las actividades, aprendieron a graficar en un plano cartesiano, pudieron ver el uso de la matemática, en este caso cuando se ponían frente al sensor y realizaban los movimientos con su propio cuerpo y observaban cómo se graficaba su propio trayecto, entre otros.

Dados esos resultados favorables de este trabajo, se pretende continuar dando a conocer estas actividades con el uso de instrumentos tecnológicos a los demás grupos de dicha escuela secundaria, para que los alumnos desarrollen las habilidades necesarias para su aprendizaje.

En este proyecto se cree que la tecnología es un factor clave para la enseñanza de las matemáticas, como mencionan en Correa, et al. (2016), respecto a la tecnología "influye no sólo en la forma que se enseñan y aprenden las matemáticas, también desempeña un papel importante respecto a qué se enseña y cuándo aparece un tema en el currículo" (p.21).

En este proyecto se pudo comprobar que, efectivamente, al implementar la tecnología en el salón de clases en materia de matemáticas, no solo hace más atractiva la clase sino que puede provocar ese aprendizaje que se desea los estudiantes obtengan.

Las limitantes de este proyecto es que se realizó con solo un grupo (salón) de alumnos de $1^{\circ} \mathrm{de}$ secundaria, los cuales cuentan con poco conocimiento sobre el tema, por ello se recomienda implementarse también con alumnos de $2^{\circ}$ y $3^{\circ}$ para ver cuál es su aprendizaje en situaciones como esta y pueda servirles para enriquecer su conocimiento.

\section{REFERENCIAS}

Briceño, E., y Cordero, F. (2012). Un estudio del uso de tecnología en situaciones de modelación del movimiento. Memorias del Primero Coloquio 
de Doctorado, pp.203-212. Cinvestav-IPN, México.

Briceño, E., y Cordero, F. (2015). Conozca al Sr. Movimiento. Actividades de interpretación gráfica de movimiento. En La ciencia desde el niño(a): porque el conocimiento también se siente (pp. 4760). Barcelona: Gedisa.

Cantoral R., y Farfán, R. (2008) Socioepistemología y matemáticas. Acta Latinoamericana de Matemática Educativa Vol. 21, pp.740-753. Recuperado de: https://www.clame.org.mx/documentos/alme21.pdf

Cantoral, R. (2016). Teoría Socioepistemológica de la matemática educativa: estudios sobre la construcción social del conocimiento. México: Gedisa.

Correa Gutiérrez, S., Reséndiz Balderas, E., Salazar Blanco, M., y Sánchez Gutiérrez J. (2016). Diseño de objetos de aprendizaje de matemáticas básicas (Geometría). México: Pearson.

Herrera García, K., y Dávila Araiza, M. (2020) Reflexión didáctico-matemática de profesores en formación inicial a través del diseño de tareas matemáticas. Acta Latinoamericana de Matemática Educativa, Vol. 33 (1), pp.580-590. Recuperado de: https://www.clame.org.mx/documentos/ alme33_1.pdf
Ibarra Cruz, S., y Rodríguez Gómez, J. (2020). Percepciones hacia el uso de la tecnología en la enseñanza de las matemáticas en estudiantes normalistas. Acta Latinoamericana de Matemática Educativa, Vol. 33 (1), pp.698-706. Recuperado de:https://www.clame.org.mx/documentos/ alme33_1.pdf

Plan Nacional para la Evaluación de los Aprendizajes PLANEA (2019). Resultados ciclo escolar 2018-2019. México: Secretaría de Educación Pública.

Santacruz Rodríguez, M. (2009). La gestión del profesor desde la perspectiva de la mediación instrumental. $10^{\circ}$ Encuentro Colombiano de matemática educativa. Recuperado de: https://core. ac.uk/download/pdf/12341336.pdf

Saucedo, A. (2014). La modelación como eje para la implementación de un laboratorio tecnológico en un aula de bachillerato. (Tesis de maestría no publicada), Universidad Autónoma de Zacatecas, México.

Secretaría de Educación Pública. Programa de estudios (2017). Matemáticas. Educación secundaria. México: Secretaría de Educación Pública. 